\title{
How Relevant is Transaction Cost Economics to Inter-Firm Relationships in the Music Industry?
}

\author{
JONATHAN GANDER ${ }^{1}$ and ALISON RIEPLE ${ }^{2}$ \\ ${ }^{1}$ University of East London, East London Business School, Barking campus, Longbridge Road, \\ Dagenham, RM8 2AS Essex, U.K. \\ ${ }^{2}$ University of Westminster, Harrow Business School, Watford Road, Northwick Park, \\ HA1 3TP Harrow, U.K.
}

\begin{abstract}
This paper applies the transaction cost framework to the organisation of product sourcing and development (PS\&D) activities within the popular music industry. Two firm types characterise the industry and this particular set of activities; large multinational firms ('majors') and smaller regionally bound companies ('independents'). We find that the Transaction Cost Economies framework of Oliver Williamson $(1985,1999)$ provides only a partial explanation for the observed hybrid organisational structures established by the two firm types. A more sensitive model can be achieved by including a number of moderating variables drawn from the socially constructed and situationally dependent idiosyncrasies of the assets involved in the PS\&D activities under consideration.
\end{abstract}

Key words: alliances, popular music industry, transaction cost economics

\section{Introduction}

Identifying, winning over and developing a musical artist or group of artists plays a critical role in the generation of value for firms operating in the popular music industry. The music industry is characterized by two principal firm types, large multinational firms such as Universal and Sony Music, which are part of entertainment conglomerates and are referred to as the 'majors', and smaller more regionally bound 'independents', often specialists in a particular music genre. The nature of their differing resources and capabilities introduces a degree of mutual dependence that results in a wide range of structural relationships between the two, from full acquisition to one-off contracts. We take the transaction cost framework of Oliver Williamson $(1985,1999)$ and examine whether it is able to provide the firms with suitable recommendations regarding their structural relationships with the other firm type. This restricted focus means we do not discuss all transactions that take place in the industry but only a particular and important subset.

The paper attempts to contribute to the literature on cultural economics in a hitherto under-examined field of enquiry - the firm and the positioning of its boundaries. The approach chosen to determine the suitable limits of the firm is Transaction Cost Economics (TCE) (Williamson, 1985, 1999; Jones, 2001). This 
institutional economics (Hodgson, 1998) perspective on cultural economic activity adds to the body of work on more established, neoclassical areas of enquiry by writers such as Baumol (1966), Rosen (1981), Cox et al. (1995) and Towse $(1993,1996)$. By exposing the TCE framework to the idiosyncrasies of a particular industry, in this case the popular music industry, we also assess TCE's ability to move beyond what Ronald Coase has termed "blackboard economics" where "the firm and the market appear by name but they lack any substance" (Coase, 1992, p. 714). In so doing the paper hopes to complement work done on other aspects of the popular music industry, including analysis of the distribution of rewards (Strobl and Tucker, 2000), industry structure (Baker, 1991), concentration (Peterson and Berger, 1975), and product differentiation (Burke, 1996; Lopes, 1992).

In Section 2 we identify idiosyncrasies present in popular music industry product sourcing and development (Breton, 1982; Throsby, 1994; Caves, 2000) and highlight the degree of comparative institutional advantage that encourages major/independent relationships. In Section 3 we provide a brief examination of how the transaction cost approach suggests managers structure their firm's activities. Section 4 assesses TCE's ability to provide firms in the music industry with sufficient guidance over structure and governance decisions having to do with PS\&D, namely whether the major acquires the independent, opts for an interorganisational solution involving co-ordinated activities, or uses the market as a source for the required competencies and assets. We argue that an application of the TCE framework would result in a recommendation of integration, although this is not what we generally see in practice. Although there are some examples of artists that contract directly with the majors, and some independents that merge with majors, not all do so, despite TCE's prediction that this would be the case. In the final discussion section, Section 5, we argue that the nature of the value-creating assets and activities critical during the PS\&D stage of the industry value system are more efficiently structured via an arms length relationship between the artist and the major, mediated by the independent. In other words, the competences and assets that characterise the identification, capture and initial musical development of new talent, introduce variables that TCE does not currently take into account when formulating governance recommendations. It is recommended that these be allowed to moderate the TCE decision framework thereby giving it some of the substance Coase (1992) was looking for.

\section{Industry Setting}

Firms in the worldwide recorded music industry can be divided into two broad types, the 5 'majors' (Universal Music Group, Warner Music Group, Sony Music Entertainment, Bertelsmann Music Group and EMI) which, with one exception, are divisions of multinational entertainment conglomerates and have a combined global market share of 76\% (IFPI, 2001), and the smaller, more locally specific firms, known as 'independents' (such as Telstar, Sanctuary, Edel). Music Business 
Table I. Value generating activities and assets involved in the creation, identification, development and exploitation of popular music product

\begin{tabular}{|c|c|}
\hline Assets involved & Value generating activities \\
\hline \multicolumn{2}{|l|}{ Product initiation stage } \\
\hline Music composing skills & Creation of a music score \\
\hline Writing ability & $\begin{array}{l}\text { Writing of lyrics that support the score and resonate with } \\
\text { the intended audience }\end{array}$ \\
\hline \multicolumn{2}{|l|}{ Product sourcing and development stage } \\
\hline Insight into future music trends & Distinguishing promising new acts from "false positives" \\
\hline Credibility and acceptability & Gaining access to and signing promising new acts \\
\hline Music and artist development skills & The creation of commercialised product \\
\hline \multicolumn{2}{|l|}{ Product exploitation stage } \\
\hline $\begin{array}{l}\text { Marketing planning producedures and } \\
\text { practices }\end{array}$ & $\begin{array}{l}\text { Creating a marketing plan, with targets, action plans and } \\
\text { timescales }\end{array}$ \\
\hline Budget management policies and skills & Providing contingent financial support \\
\hline Distribution Network & $\begin{array}{l}\text { Ensuring widespread availability of the musical product } \\
\text { Employing widespread, but locally knowledgeable, } \\
\text { regional contacts (e.g., U.S.) to maximise sales } \\
\text { internationally }\end{array}$ \\
\hline $\mathrm{PR} /$ promotional competences and contacts & $\begin{array}{l}\text { Delivering a timely and co-ordinated promotion of the } \\
\text { artist(s) and their product across a variety of media }\end{array}$ \\
\hline
\end{tabular}

International (MBI) defines independents as "companies who derive most or all of their profits via the direct exploitation of music copyrights ... whose shares are at least $50 \%$ owned separately from the multinational music majors and who were not originally bankrolled by any of the majors" (MBI, 1998, p. 11). Implicit within this definition, and critical to an understanding of the music industry structure, is the fact that the independents are, for the most part, owned and managed by the individuals who set them up, and are, due to this and their smaller size, less bureaucratic than the majors.

It is useful to view the activities required to bring music product to market in terms of value system chains (Porter, 1985) of distinct value generating activities performed by firms within an industry. The progression from product sourcing and development to eventual sales includes: the creation of music by the artist(s), its initial performance usually in small social gatherings (clubs, bars), the discovery of the artist(s) by a talent scout (referred to in the industry as Artist and Repertoire $(A \& R)$ ), a period of refinement where the artist's musical style is developed, followed by an exploitation phase for which co-ordinated promotion and distribution plans aim to maximise sales of the product (album/single) and the profile of the $\operatorname{artist}(\mathrm{s})$. 
Within this sequence it is possible to identify a large number of transactions between a variety of individual and organisational actors. We have summarised these in the table below, although in this paper we will only be examining a subset of these, those to do with the sourcing and development of new musical talent. These are: knowledge of future music fashions; credibility; and music development. We will return to this table later when we discuss TCE's ability to predict an optimal governance structure for such a subset of activities. First we discuss these three transaction contexts. As we examine each in turn, their institutionally dependent and socially constructed qualities become apparent.

\subsection{INSIGHT INTO FUTURE MUSIC TRENDS}

In the recorded popular music industry, the spotting of new musical trends and the artists that epitomise them is a critical success factor (Belinfante and Johnson, 1982). As with any industry subject to short product life cycles and rapid changes in demand, an ability to monitor and understand the environment improves a music firm's ability to compete. With such knowledge firms can anticipate shifts in demand and alter their roster of artists both to take advantage of the surge in sales that accompanies new talent or a new musical direction and to reduce the risk of being left with a large number of artists whose product is no longer in demand. The latter occurred notoriously after the sudden fall in demand for "Disco" music in 1980 (Elliot, 1993) and more recently when interest in U.K. "Brit-pop" similarly declined (Taylor, 1998).

Music creation, as distinct from its production, is not dependent on large resources, requiring at its most basic level a guitar, pen and paper. Such low entry barriers, in addition to the presence of intrinsic rewards when making or performing music, allow for very large numbers of competing artists (Throsby, 1994; Hirsch, 1972). Firms can receive 300 to 400 speculative samples of music a week (Passman, 1994). This oversupply makes the task of identifying emerging talent and distinguishing it from the host of "false positives" extremely challenging.

The value of knowledge concerning future musical trends is further enhanced when the distribution of sales is considered. The popular recording music environment is one in which increasing return conditions (Kretschmer et al., 1999) and the "superstar phenomenon" (Rosen, 1981; Adler, 1984; Hamlen, 1991) lead to huge differentials in sales between those artists who are successful and those who are not (Cox et al., 1995).

To add to the challenge, the process whereby musical talent is identified and signed is undertaken in a highly socialised environment with information on new acts being transferred informally and selectively (Caves, 2000). Membership of, or at least social contact with, members of the relevant social groups is required if such information is to be obtained in a timely manner and useful form. Such participation as an insider is aided by a degree of social congruity such as that possessed typically by the independent's staff who are careful to retain and protect 
social similarities so that they are not hampered by the commonly-reported mistrust of the multinationals (Hesmondhalgh, 1998).

Those who are believed able to access knowledge and use it to predict future trends are likely to be in great demand along with those who do not have such knowledge, but can exploit it. Although there are exceptions to this rule, such distribution of skills tends to favour, in the first case, the independent, and in the second, the major (Frith, 1990). There is therefore the possibility for transaction between the two firm types, and there are many examples such as those between the independent, Creation (with Oasis on their roster) and Sony Music Entertainment; Zomba (who have Britney Spears) and Bertelsmann; Telstar (who have Craig David) and Warner Music Group.

\subsection{CREDIBILITY}

Credibility refers to the ability of the firm to inspire trust in the artists who are likely to emerge as future high-selling acts. The need for trust is a particular issue at the early stage of an artist's career, when they lack the knowledge and experience to protect their own interests and make effective decisions.

A difficult balancing act is required as artists often want to make a high return from their music, whilst simultaneously retaining the respect of their peers and achieving their musical ambitions without outside interference. A response to the sizable knowledge asymmetry between the more experienced music firm and the inexperienced artist is to sign a contract with the firm seen as most likely to look after their best interests and not "sell out" to those who will exploit them or ignore their artistic sensibilities (Hesmondhalgh, 1998). Framed in this way, independents, by virtue of their smaller size, less bureaucratic structure and more informal culture, often have an institutional advantage over the larger corporate majors when it comes to credibility. Credibility's contribution to an effective PS\&D operation is given additional weight as it is subject to increasing returns. Artists signed to a music firm can act as a magnet, by providing validation they encourage other artists to join (Negus, 1999).

\subsection{MUSIC AND ARTIST DEVELOPMENT}

Initially the artists' music is not typically in a commercial form. In order to bring such product to market, the independent and the artist have to shape the music into a form that is suitable to be sold as an album in terms of length, number, and balance of tracks. Such a transformation process requires both an understanding of the marketplace as well as a sensitivity to the non-standardised ways in which a creative product develops (Stinchcombe, 1959; Amabile, 1996). This needs a managerial style that is at the same time directive and responsive. The independent, being unencumbered by the bureaucratic requirements of the major, is in a better position to offer a less structured and more enabling environment, in which 
what Garnham (1987, p. 58) has referred to as "the expression of difference" can co-exist with commercial requirements (Lampel et al., 2000). In other words, the independent uses cultural and aesthetic criteria to control the outcome, rather than bureaucratic procedures (Leifer and Mills, 1996; King and Zeithaml, 2001).

\subsection{COMPARATIVE INSTITUTIONAL ADVANTAGES}

The two firm types, independent and major, have, since the beginning of rock and roll in the mid 1950s, had an intertwined history, with relationships covering a wide range of structural and governance types, from full acquisition to one-off distribution deals (Negus, 1992). The rationale for such deals appears to be based on a certain coagulation of assets around the two firm types. Scale economies, capital resources, marketing competencies and distribution reach reside with the major, while the independent, with its greater social congruity and ideological empathy with emerging artists, has an advantage over the larger and more culturally distanced majors when spotting and developing new talent (Frith, 1990).

This division of comparative institutional advantages plus the high demand for new talent ensures that the major music firms frequently use the independents for PS\&D activities (Negus, 1999; Hesmondhalgh, 1998). Our own research found that 112 inter-organisational deals between the major and independent were initiated between 1993 and 1999. The prevalence of this structure makes the governance mode chosen to mediate the exchange important.

A further aspect of the industry gives this decision additional importance. Other activities within the music industry value chain involve the exploitation of resources that are imitable, mobile and broadly homogenous, (publishing, promotion, distribution) and as such offer little opportunity to develop competitive advantage. However the resources involved in the identification, attraction and development of new talent, due to their causally ambiguous, complex and heterogeneous nature, do offer such potential (Barney, 1991). The discussion of TCE's suitability to advise the major type in its selection of governance method to handle such frequent and important transactions is therefore both relevant and significant.

\section{Transaction Cost Economics}

Before we discuss the elements of Transaction Cost Economics that are particularly relevant to the PS\&D process within the recorded music industry, we briefly discuss some of the main aspects of the TCE framework.

TCE is most closely associated with the work of Williamson (1973, 1981, 1985, 1991), although it has since been copiously critiqued, built on, and in some cases muddied (Ghoshal and Moran, 1996; Osborn and Hagedoorn, 1997; Holmstrom and Roberts, 1998; Slater and Spencer, 2000; Jones, 2001). Developed from inquiries into the reason for the presence of firms, TCE's answer rests on the presence of costs in the organisation of economic activity, or transactions, and cost differen- 
tials between operations carried out within the firm and bought on the open market. These costs are incurred when negotiating, monitoring and controlling exchanges and come about due to the need to monitor performance and safeguard elements of production and know-how. Transaction costs are influenced by the nature of the resources and activities involved and the characteristics of the business itself, and also by the degree of uncertainty in a firm's environment.

These transaction costs can usefully be viewed as "the economic equivalent of friction in physical systems" (Williamson, 1985, p. 19). The governance structures available to organise these transactions, such as ownership (also known as hierarchy), buying in the market place, or an intermediate form such as a joint venture, can be chosen according to their ability to reduce this friction and thus minimise the costs of doing business. Generally speaking, the higher the costs involved in buying in the marketplace relative to the costs of making in-house, the greater the recommendation to internalise the transaction and bring it within the control of the firm's hierarchy, and vice versa. Where costs are more balanced, a mixed form, such as a joint venture or strategic alliance, is implicated, although, as we argue later, the increasing trend towards this sort of form in some industries may actually be driven as much by other factors as it is by TCE's premises.

TCE theory suggests that transaction costs arise principally as a result of three individual factors, but also from the interactions between them (Williamson, 1985). These factors are bounded rationality, asset specificity and opportunism. Bounded rationality refers to the fact that individuals are necessarily limited in their ability to "receive, store, retrieve and process information without error" (Williamson, 1973, p. 317). Bounded rationality, which Williamson interpreted in a somewhat heterodox way from Simon's (1957) original conceptualisation (Slater and Spencer, 2000; Dequech, 2001), ensures that complete contracts, which can anticipate all eventualities, cannot be written nor future opportunistic behaviour unfailingly anticipated/spotted. Asset specificity points to the degree to which a resource can, if required, be redeployed to alternative use without the loss of productive value. Opportunism describes the possibility that parties attempt to gain advantage through deceit, or "self-interest seeking through guile" (Williamson, 1981, p. 554).

In terms of interactions between these factors, assessing the costs arising from opportunism requires some form of assessment of the likely impact of contractual incompleteness (i.e., bounded rationality). TCE does not claim that man is inevitably opportunistic, rather that there is the chance that some parties may be, and the possibility that actors, normally assumed to be those located outside the firm, could act opportunistically introduces a cost into the transaction. The nature of this cost depends on the assets or resources involved. If the resources affected by opportunistic behaviour can be used elsewhere in the firm to similar productive value, i.e., they are not specific to the transaction under consideration, then the costs of protecting against such behaviour is low. However, should the resources be specific to the particular transaction, then redeployment is more problematic and costs are amassed as the productive capability of all or part of the asset is 
lost. The notion of asset specificity is therefore a crucial variable, as Williamson described it, the "big locomotive" (1985, p. 56) driving the assessment of the costs of opportunism.

A consequence of this is that one important element of TCE is its focus on the potential for hold-up resulting from opportunism and transaction-specific assets or sunk costs that occurs when an exchange relationship has to move from an openly competitive market situation, with large numbers of potential partners, to one of relationships between a small number of irrevocably-committed trading partners. Under these circumstances there is a fundamental transformation in bilateral power dynamics, and external suppliers can no longer be considered to be perfect substitutes for insiders (Williamson, 1985; Ghoshal and Moran, 1996; Holmstrom and Roberts, 1998; Ricketts, 2001). Once assets are thus transformed, transactions between small-numbers partners are in need of safeguards and costs are accrued as the result of monitoring and enforcing such transactions. TCE would therefore predict that hierarchy is a better form of controlling such transactions as the costs will be lower.

However, the fundamental transformation in power dynamics may not be as predicted in environments where there need not be any ex-ante expenditures at all, but simply a "costless choice of partner or standard or something similar that limits a party's later options" (Moran and Ghoshal, 1996). That is not to say that these "investments" do not alter the power balance - they do, but not necessarily in the direction that TCE would predict. The framework's "indifference to the level of initial investments" (Holmstrom and Roberts, 1998) is also based on an assumption that the carrying out of such investments is fully contractible, a problematic assumption when the investment is simply a promise to exclude other partners. In such circumstances, trust and reputation may be more important power, and thus cost, determinants (Rieple et al., 2002).

In fact, behind much TCE-based writing lie a number of assumptions, for example, that the costs of transacting in-house are less than those of transacting externally. However, the calculation of costs is a tricky problem and, with few exceptions, is one that has been all but ignored in previous research (Buckley and Carter, 1996). Some of TCE's other premises can also be challenged. For example, TCE assumes that owners of firms can measure and reward behaviour as well as output, which allows them to detect opportunism and exercise administrative fiat, process information efficiently and deploy assets more flexibly, thereby reducing costs (Rindfleisch and Heide, 1997).

Though Williamson (1996, p. 55) states that TCE "is an empirical success story" concern has also been voiced around a number of other key components of the TCE decision framework, namely its focus on cost-minimisation at the expense of value-creation, which results in missed opportunities and thus sub-optimal firm performance (Zajac and Olsen, 1993; Dyer, 1997), the assumption of risk neutrality (Chiles and McMackin, 1996), the centrality of opportunism (Ghoshal and Moran, 1996), and TCE's generally undersocialized and a-historical nature (Granovetter, 
1985; Ring and Van de Ven, 1992; Argyres and Liebeskind, 1999). This results in a "temporal reductionism" (Gulati, 1998, p. 302) that paints a static picture of firm activity and decision making (Lorenzoni and Lipparini, 1999; Gulati, 1995b). Indeed Williamson (1996, p. 239) himself has admitted that his theory is one based on "comparative statics".

A number of writers have pointed out that people do not make choices as isolated individuals, but within historically constituted social relations that are context and time-contingent (Slater and Spencer, 2000). However, TCE rarely deals, even peripherally, with the issue of temporality (Gulati, 1995a). This is an important problem when there are repeated transactions between the same individuals and also relevant to the time over which a key element of TCE, bounded rationality, is meaningful and future transaction costs therefore calculable.

Williamson's (1996) introduction of the concept of "farsightedness" attempts to resolve the apparent contradiction that agents can be boundedly rational, yet able to identify the limits of their rationality. Farsighted agents can anticipate the consequences of the limits of their rationality by assigning probabilities to future events and organising transactions accordingly. However, this does not negate the charge of temporal reductionism. TCE's emphasis is placed on the farsighted agent's ability to, a priori, create suitable governance structures. This assumes a deterministic view of life ignoring the potential for the future to be complexly dynamic and recursively transmutable (Slater and Spencer, 2000). As Pratten (1997) suggests, "the failure to recognise that the social world is open and dynamic leaves TCE imparting determinacy to an indeterminate reality".

Introducing time into TCE could, in fact, eliminate any role for transaction cost calculations, since a notional perfectly-known long-term would then exist, bringing universal market contracting and making short-term transaction cost calculations redundant (Slater and Spencer, 2000). This would also apply where market conditions are unchanging, when conditions are known and predictable. However, in environments characterised by frequent and volatile disturbances there is greater opportunity for opportunism and less recourse to a contract for protection against it. Contractual 'gaps' will be large in such an environment as they cannot cover the wide and unknown range of eventualities possible, making hierarchy the theoretical structure of choice.

Similarly, the more complex the transaction, the more difficult it is to identify the commitment, effort and skill deployed by a transactional party (Williamson, 1981). Encouraged by the reduced likelihood of being caught as the result of this complexity and, thus, uncertainty, of the situation, self-interested opportunistic behaviour can result. Opportunism is also "encouraged" when exchanges are subject to small numbers trading conditions. With a limited number of suitable trading partners, there is the possibility of opportunistic pricing and/or a bidding war inflating the costs of purchase and risking the negation of any future operational profits. All of these suggest hierarchy as the way to deal with such issues, and yet there are many examples of industries with innovative characteristics where hierarchy as a 
structure appears to be in decline (Ricketts, 2001; Nassimbeni, 1998; Holmstrom and Roberts, 1998; Gulati, 1995a), implying that TCE as a working theory may be flawed or require adjustment.

Although some of these recent developments of TCE theory have necessarily adapted or accommodated its original assumption of stasis (Williamson, 1991, 1996; Jones, 2001), TCE can still be accused of failing to deal adequately with the issues of organisational learning and adaptation and the management of dynamic resources such as tacit knowledge (Mosakowski, 1998; Slater and Spencer, 2000). Foster (2000) suggests that to survive in an evolving environment, the firm's capabilities must keep on changing, and with them, input-output relationships. Static efficiency considerations are thus less important than those concerned with dynamic efficiency, and institutions such as habits, norms, and conventions, figure more prominently in structural decisions than transaction costs.

Similarly, TCE's tendency to focus on factors that can guard against negative behaviours such as opportunism rather than on positive collaboration and trusting relationships ignores other "important elements of human disposition" (Moran and Ghoshal, 1996). It can therefore be accused of being unrealistic, and thereby, if implemented, would in fact achieve the opposite of its intended effects. This would happen through the heightening of conflict, a reduction of the potential for mutual gains, and limiting of the means by which order may be accomplished. Although we would perhaps not go quite so far as Moran and Ghoshal, the notion of opportunistic behaviour being the most important factor governing transactional relationships in the context of highly inter-connected social networks, as most industries and markets are, is certainly an area of concern. As Foster says, TCE can be useful, but only if it takes into consideration "in a much more explicit manner than has hitherto been the case, the motivational dispositions of individuals engaged in economic activity" (Foster, 2000). It can be argued that some of these motivational dispositions form part of an organisation's atmosphere, in effect its culture or climate, which emphasises the social aspects of an organisation and fosters a sense of belonging and mutual dependency among its members. Williamson (1975) briefly acknowledges that organisational atmosphere can reduce opportunism as well as enabling congruence between individual agents and their employer's goals. However, this construct has strangely been rather neglected in subsequent developments of the TCE framework.

Although TCE focuses principally on two structural alternatives, hierarchy and market contracting, a third type of structure can be identified in which transaction costs are not seen as high enough to justify internalisation, yet represent a sufficient cost to make the conducting of transaction solely through the market unsuitable. The resulting structure is a hybrid - a sustained relationship between two or more firms. These take a number of different forms including joint ventures, agreements to trade, strategic alliances, and even, arguably, to long-term but informal relationships between two firms, in which no explicit contracts are written or expected (Nassimbeni, 1998). However, as Powell (1987) suggests, and as we also argue 
below, TCE appears inadequate to deal with the range and complexity of the hybrid structures that are seen.

In hybrid structures, collaboration is a key feature. Collaboration is neither a market exchange, nor hierarchy. "Whereas hierarchical control is associated with a willingness on behalf of participants to submit to both direction and monitoring by those in positions of legitimate authority, collaboration involves the negotiation of roles and responsibilities in a context where no legitimate authority sufficient to manage the situation is recognized" (Phillips et al., 2000). This means that power dynamics based on the exchange of heterogeneous, and potentially non-tradable, resources is an important issue and the calculation of transaction costs may be irrelevant, as well as tricky, or indeed impossible. As we argue below, where specialised human capital is the contractual problem and where control of one type of asset is best held by one type of transactor and control of a different type is important for the other, hierarchical integration within a single firm is not necessarily the best option whatever the theoretical costs.

For example, the hybrid structures characteristic of the relations between Japanese manufacturing firms and their suppliers are one example for which TCE's make or buy dichotomy has been problematic (Holmstrom and Roberts, 1998). These structures comprise long-term, close relations between independents that seem to mix elements of market and hierarchy, and appear to act as substitutes for control via ownership in protecting specific knowledge-intensive assets such as product design. Using TCE as a predictive theory, the potential for holdup resulting from both asset-specificity and opportunism would predict in-house development, because investment in design is highly situation-specific and unprotectable by contracts. Instead, in Japan much of the design component is carried out by independents. Such structures have parallels with those found in the music industry, and as Holmstrom and Roberts (1998) suggest, are becoming increasingly prevalent in other parts of the world and in other knowledge-intensive industries.

Thus, in addition to some of the generic critiques of TCE, there also exists concern for TCE's applicability to specific industry sectors (Murray and Kotabe, 1999; Pessali and Fernandez, 1999), or indeed to managers in real-life situations. According to Barringer and Harrison (2000), when Faulkner (1995) explained TCE's concepts to executives who had been involved in forming alliances, none of those interviewed indicated that transaction costs had formed part of their decisionmaking over the choice of structure. The fact that tension exists between a specific context and a generic interpretation of TCE is not, of course, remarkable in itself, being an endemic feature of theory construction and development (Poole and Van de Ven, 1989; Jones, 2001; Slater and Spencer, 2000). Taking Sutherland's (1975, p. 9) definition of a theory as "an ordered set of assertions about a generic behaviour or structure assumed to hold throughout a significantly broad range of specific instances", what is of interest is the outcome of such tensions, the range of specific applications in which a theory remains valid. Testing against a specific context such as the popular music industry therefore identifies the core elements and strength 
Table II. Music industry asset specificity and shapers of opportunistic behaviour

\begin{tabular}{|c|c|c|}
\hline Assets & Value generating activities & Potential shaper of opportunistic behaviour \\
\hline $\begin{array}{l}\text { Insight into } \\
\text { future music } \\
\text { trends }\end{array}$ & $\begin{array}{l}\text { Distinguishing promising new } \\
\text { acts from "false positives" }\end{array}$ & $\begin{array}{l}\text { Information and power asymmetry } \\
\text { Ex ante valuation of knowledge } \\
\text { Uncertainty of product success } \\
\text { Small numbers bargaining } \\
\text { Search/wide net costs }\end{array}$ \\
\hline $\begin{array}{l}\text { Credibility } \\
\text { and } \\
\text { acceptability }\end{array}$ & $\begin{array}{l}\text { Gaining access to and } \\
\text { signing promising new acts }\end{array}$ & $\begin{array}{l}\text { Small numbers bargaining } \\
\text { Monitoring of dynamic and complex environment }\end{array}$ \\
\hline $\begin{array}{l}\text { Music and } \\
\text { artist } \\
\text { development } \\
\text { skills }\end{array}$ & $\begin{array}{l}\text { The creation of a } \\
\text { commercialised product }\end{array}$ & $\begin{array}{l}\text { Information asymmetry } \\
\text { Uncertainty of product success } \\
\text { Monitoring of complex/dynamic environment }\end{array}$ \\
\hline
\end{tabular}

of the theory and also identifies the areas for which modification or extension of components is required (Weick, 1989). Hence we now examine TCE against the product sourcing and development components of the recorded music industry.

\section{Application of Transaction Cost Economics Framework to Popular Music PS\&D}

We argue that applying the TCE perspective to the transactions involved in product sourcing and development activities (PS\&D) within the popular recorded music industry results in a high cost assessment. Given the comparative institutional advantage held by the independent in regard to PS\&D activities, the cost assessment translates into a recommendation to integrate (acquire). The requirement for hierarchical control stems from issues surrounding asset specificity, metering difficulties, environmental uncertainty and the potential for small numbers bidding and pricing.

A brief outline of the analysis leading up to the above outcome is discussed below and summarised in Table II. This enlarges Table I to include an assessment of the factors potentially shaping opportunistic behaviour in the music industry. TCE's third fundamental, bounded rationality, is assumed.

The above transactions are all complex, using intangible knowledge and involving processes that are difficult to monitor and assess. The more complex the transaction, the more difficult it is to identify the level of commitment, effort and skill deployed by an agent or party (Williamson, 1981). The resulting cloud of doubt and uncertainty can be exploited, and, encouraged by the reduced likelihood of being caught, self-interested opportunistic behaviour can result. With 
its non-standardised, craft like production processes (Stinchcombe, 1959) and an almost total dependence on the market to determine quality, the possibility for opportunism and thus the major's exposure to the costs of opportunism is increased.

If the major had little staked on the transactions and could pull out and redeploy its assets elsewhere with little or no loss in value, then the cost of opportunism enabled by such complexity and metering difficulties would be low. Integration as a protection mechanism would not be required and a mixed form such as a joint venture or long-term contract would be more suitable. However the major makes two categories of investment that require protection from the costs of opportunism: (a) investments in its own organisation that are specific to the transaction and would drop in value if they had to be "moved elsewhere", and (b) investments in the partner's assets that could not be recovered if the relationship, for example an alliance or joint venture, was subject to opportunism.

Investments by the major involve human assets in the form of teams and individuals who over time develop knowledge, skills and understanding of the individuals and products (artists) that make up the independent record company. These skills, knowledge and trust levels are highly particularised, highly specific to the individuals involved and thus cannot be transferred to another independent. Other investments made in the artist and independent would also, in the event of termination, be difficult to recover. Although property rights in terms of the product (music) may be clear and enforceable - the major can, for example, demonstrate and receive a proportion of revenue from record sales or performance royalties, what is more problematic is the investment made in the artist and the independent company. The intangible skills and knowledge held by individuals and powered by a network of relationships and working practices represent a set of assets whose value is difficult to calculate or transfer, being tied to specific relationships with artists, members of particular musical scenes (club owners, journalists, promoters, niche customers) and among themselves.

\subsection{ENVIRONMENTAL VOLATILITY}

Further indication that a transaction cost perspective would result in the recommendation to integrate such exchanges can be found in the high level of environmental volatility within the music industry. The more exogenous disturbances, the argument goes, the more uncertainty surrounding the response of a party to that change, and thus the greater the opportunism potential. The popular music industry environment is one that is defined by rapid and violent change. With the extremely high concentration of sales across a limited number of artists (Cox et al., 1995), successful bands enjoy supernormal returns and the value of an artist/band can rocket, dramatically increasing their bargaining power. Under such conditions the "machinery to 'work things out' - since contractual gaps will be larger and the occasion for sequential adaptations will increase in number" as Williamson (1985, p. 60) notes, is clearly vital. Thus it follows that integration is recommended, by 
providing mechanisms for discussing and adapting to changed circumstances. Hierarchical structures are seen within the TCE model as being better able to respond to changes, primarily through the use of fiat as a last resort (Williamson, 1999; Zajac and Olsen, 1998; Argyres and Liebeskind, 1999).

\subsection{SMALL NUMBERS BARGAINING}

The presence of small numbers trading conditions appears to underline the requirement to bring music industry PS\&D activities within one firm. With a limited number of suitable trading partners, there is the possibility of opportunistic pricing and/or a bidding war inflating the costs of purchase and risking the negation of any future operational profits. At first sight small numbers bargaining does not appear to be relevant in PS\&D activities. Indeed such a suggestion appears counterfactual for an industry with an acknowledged oversupply of potential product in the form of artists (Towse, 1996; Hirsch, 1972). Low entry barriers (only a musical instrument or computer is needed), low creation barriers ( 3 minutes of song lyrics and musical score) and high levels of intrinsic satisfaction enable and encourage artists to produce a large amount of product. However a number of factors combine to counteract this large numbers context. The large choice of possible investments increases the cost of discovering which one is suitable. This, when compounded by difficulties in ascertaining the quality of a cultural product (Hirsch, 1972), produces a concentration of interest on a small number of artists, usually from known successful talent spotters employed by the independents. Such conditions encourage bidding wars and offer independents the ability to engage in opportunistic pricing.

\subsection{INFORMATION ASYMMETRY}

Information in this industry is unequally distributed with respect to both knowledge of future music fashions and music and artist development. As argued earlier, knowledge of future music trends is predominantly held in the heads of those individuals who work for the independents. They are close to trends and fashions and are situated within the very tight, and exclusive, social networks of musicians and musical genres. This information imbalance makes the valuation of those acts recommended by the independents difficult and contractual details hard to specify. The potential cost of such asymmetry is exacerbated by the time required to discover the true worth of the original judgement. It can take a year or more to develop the musical style of an act, create records, promote them and distribute their product.

\subsection{MONITORING/METERING DIFFICULTIES}

Whilst adherence to a promotional schedule that can involve an agreed number of interviews, promotional trips and other public appearances can be monitored, mea- 
sured and controlled, the recording of an album, involving tacit (Polanyi, 1966), socially constructed, and contextually dependent knowledge is less suited to control through formal reporting procedures. The result is that a major can contract with an artist or an independent label for a defined number of albums within a certain time period, yet cannot distinguish between hold-ups in the creation of such albums due to collaborative, mutually beneficial behaviour, say because the artist is striving for something that will become a hit, or the result of non-compliance. Thus the causal ambiguity and complexity surrounding product creation, quality and effective monitoring allows a disgruntled artist to honour a contractual stipulation without necessarily delivering a successful product. Though damage to the artist's reputation is a possibility if inferior or no product is released, something which probably encourages a degree of commitment, compilation albums, acoustic work, and concept albums, can allow an artist to preserve their reputation whilst complying in name only with the terms of their contracts.

\section{Discussion}

We have discussed how a TCE based analysis would result in the recommendation to integrate PS\&D activities within the major's hierarchy. We have argued that due to the large numbers of potential artists and certain institutional advantages when attempting to identify and capture the few who can become commercially successful, this translates into the acquisition of the independent. However, a preliminary study (Rieple and Gander, 1999) into major/independent relationships found only limited empirical support for this prediction.

Using the Financial Times' specialist publication on the music industry "Music and Copyright" we were able to identify 105 major/independent inter-organisational agreements initiated during the period 1993 to 1999. Inter-organisational relationships involving publishing, broadcasting, multi-media or film were excluded from our assessment. The data were classified according to Williamson's (1999) conceptualisation of hierarchy, hybrid and market based governance types. Two distinct categories emerged: hierarchy (acquisition) and hybrid form (joint venture/long-term agreement ${ }^{1}$ ). One-off, market-based, transactions were not evident from this source. Cases classified as an acquisition involved the purchase of a majority share of the independent. In the cases reported, 28 of the 31 acquisitions were of $100 \%$ of the independents' equity, and three were majority purchases of 51, 73 and $90 \%$ respectively. Hybrid governance structures, of which there were 74 , were those characterised by long-term contractual agreements between the major and independent, perhaps with some form of minority equity purchase of the independent, or a shared ownership arrangement where the major established a joint venture with the independent. Thus only $30 \%$ of our sample evidenced the integration, through acquisition, of the PS\&D assets of the independent. The remaining $70 \%$ of governance modes were hybrids. 
We do not claim to have captured all music industry transactions during this period, as our restriction to those cases reported in the music press means that a number of smaller deals may have gone unreported. Similarly, internal transactions carried out within the hierarchy of the majors cannot be identified, although interviews carried out with senior managers of Sony Independent Network Europe and their independent partners (article in preparation), along with industry commentators such as Hesmondhalgh (1998) and Negus (1992), suggest that these percentages are not untypical of the industry's activities.

Williamson (1985) offers an alternative model of inter-organisational structure for occasions in which transaction costs are high enough to recommend integration, but in which another form is more suitable for the activities under consideration, in the short term at least. These are hybrids such as joint ventures, strategic alliances etc. Where activities required high levels of incentivisation the incentive dampening characteristics of a bureaucratically organised hierarchy may be detrimental. Consequently even high transaction cost exchanges would be better organised via a two-stage approach. In such cases it is argued that once the incentive dependent product creation and development stages are complete and the resulting product moves into its exploitation phase it can be acquired and exposed to the process efficiency of a bureaucracy without fear of value destruction.

The product sourcing and development of new musical product clearly falls into this category. However, the recommended solution, to delay integration until innovation has taken place and the result requires the more ordered exploitation suited to the bureaucratic organisation, relies on a Schumpeterian view of innovation, in which revolutionary changes in technology (Dewar and Dutton, 1986) offer long revenue streams and the presence of an identifiable period in which to manage the transfer of ownership prior to its exploitation. Such a view does not describe the more trend-dependent, short-term or continuous innovation patterns (Nonaka and Takeuchi, 1995) characteristic of the development of new artists and their output. It is arguable that these concerns lay behind Sony's refusal to take up the option to buy Creation Records (home to the highly successful Oasis band) when it fell due, preferring instead to offer the two founders a $£ 12$ million payment to continue the hybrid arrangement (Rawsthorn, 1996).

Whilst there is indeed a very marked distinction between the identification and creation of cultural product in the form of an album and its subsequent exploitation through co-ordinated marketing campaigns across the various media channels, the short life-cycle of the product ensures that there is a very real possibility that the process of negotiating any integration or partnership would take longer than the sales cycle of the product. Integrating a firm in order to exploit the results of its innovation would only reliably apply to previously released music (the back catalogue), valuable for only a minority of superstars (U2, The Beatles, Prince). The formation of a hybrid organisational structure to smooth any decision to integrate via the pre-installation of the necessary channels of communication and the 
possible use of contractual clauses giving the partner firm first option on purchase can, of course, speed this process up, but, arguably, not sufficiently.

Recognising that another variable outside transaction cost's principal elements could overrule the recommended transaction cost outcome suggests that other variables could similarly serve in a qualifying role given the situationally dependent, socially constructed and ultimately intangible nature of the assets involved in popular music PS\&D.

\subsection{NON TRANSFERABILITY}

PS\&D assets, such as competences in trend spotting, talent identification, talent capture and early management, are typically held by the independent and are reliant upon environmental and procedural factors that are embedded in the culture of the organisation. The attempted transfer of these creative assets into a different institutional environment risks separating them from their context, and thus depriving them of the requisite conditions for their exercise (Powell, 1987; Szulanski, 1995; Madhok, 1997; Kostova, 1999). This is especially the case when the environment in question is within a large multinational conglomerate better suited to the operation of standardised and well understood production processes (Powell, 1987), not the non-linear causally ambiguous and contextually dependent creative processes (Pilditch, 1990) involved in PS\&D. TCE's de facto bias towards tangible assets makes for discomfort when it is applied to exchanges involving intangible assets such as knowledge and reputation (Lorenzoni and Lipparini, 1999; Noorderhaven, 1996; Kogut and Zander, 1995). Yet it is the cultural knowledge of the independent, required to spot new musical trends and attract new musical talent, that forms at least part of the explanation for differential firm performance within the music industry (Grant, 1996: Teece, 1998, 2000).

\subsection{NEGATIVE EXTERNALITIES}

Reputation effects are also relevant to the independents and need to be considered in any governance decision (Gander and Rieple, 2001). As we discussed earlier, the reputation, or credibility, of the independent type and its personnel plays a key role in signing new talent. Yet this asset is vulnerable to too close an association with a major, due to the latter's perceived anti-aesthetic, pro-commerce, attitude. Though the hostility between the two firm types can be overstated (Hesmondhalgh, 1998), it is there, and the integration of an independent into the hierarchy of a major risks, due to network effects, degrading this asset.

\subsection{OVER-RELIANCE ON ADMINISTRATIVE CONTROL}

In addition to the argument that the assets required for optimal PS\&D will not transfer unharmed into the major's hierarchy, the theoretical ability of a hierarchy 
to minimise transaction costs also applies to only a limited extent in the context of the music industry. Though metering difficulties created by the causal ambiguity and complexity of PS\&D activities would point to integration, the nature of the assets involved would also suggest that seeking to control and protect them by placing them within the major's hierarchy is self-defeating.

Although some highly creative workers undoubtedly do respond to directives based on administrative authority, there remains the problem of identifying whether the behaviour of those that don't is actually opportunistic. Conventional monitoring and measurement procedures based on supervision and conformance to reporting standards can simply fail to capture what is a non-linear, creative productdevelopment process (Leifer and Mills, 1996; King and Zeithaml, 2001). An artist's adherence to a promotional schedule that can involve an agreed number of interviews, promotional trips and other public appearances can be monitored, measured and controlled to some extent. However, the A\&R agent's search for new artists, the building of relationships with them, and the eventual recording and development of an album, all involve tacit (Polanyi, 1966), socially constructed, and contextually dependent knowledge that is ill-suited to control through formal reporting procedures. Due to their tacit status, attempts to record, say, the number of concerts attended by the A\&R agent or discussions held with artists, only capture effort and not the effective utilisation of PS\&D assets.

For example, the major will find it difficult to distinguish whether a hold-up in the creation of a best-selling album is because there are no promising bands available at that time, because an artist is striving to improve something that will eventually become a hit, or because of non-compliance. Secondly, the effectiveness of PS\&D activities is only knowable upon release of new into the marketplace. This is in contrast to classical music, for which acknowledged metrics such as sound quality, orchestra skill, and musical arrangement can be used to estimate progress and spot non-compliance. No such established quality standards work effectively ex-ante in the popular music sector.

In fact, the use of formal monitoring and control procedures, as well as failing to spot and/or curtail opportunistic activities, may actually be counter-productive. Tight control procedures have the potential to encourage a spiral of distrust, thus encouraging rather than diminishing self-seeking behaviour (Lorange and Roos, 1992; Ghoshal and Moran, 1996; Wicks et al., 1999), a particular problem in an industry that is already defined in terms of institutional distrust. The culture meets commerce paradigm is evidenced in the "them and us" discourse used by actors in the industry, ${ }^{2}$ and epitomised by Allan McGee, head of a successful independent, Creation, who described staff at a major with whom his company had an alliance, as "nice people but not my people" (Guardian, 2000). 


\section{Conclusion}

The identification, attraction and development of new artists represents a critical set of activities within the popular recorded music industry (Belinfante and Johnson, 1982). The resources required to carry out such functions are frequently sited within relatively small independents that are connected to new and developing music scenes. A union with the superior economic resources of a major music company to exploit the results of such research and development would appear to represent a complementary match of assets. An application of transaction cost economics to the structuring of such a union would recommend the internalisation of the independent into the major's hierarchy, because of concerns over asset specificity, monitoring and measurement complexities and the degree of environmental uncertainty.

However, integration is not observed in PS\&D transactions between the two firm types as much as one would expect, and thus TCE appears to be inappropriate or only of limited applicability when applied to this industry. This paper suggests that aspects of the assets involved in creative music development, notably their reliance upon institutional and environmental factors for their effective use, and the critical role that reputation plays in their overall operation, means that they would be subject to value erosion upon their incorporation within a single hierarchy, that of the major. Whilst Williamson (1996) notes the limits of bureaucracy within TCE's framework, the moderating variable is limited to incentive impairment, and Williamson states that he is awaiting progress in the "undeveloped" understanding of bureaucratic failure. Our paper provides a partial explanation for this, within one industry type.

Our paper suggests that PS\&D activities within the popular music industry introduce additional moderating variables to a transaction cost approach. Taking Weick's (1989) recommendation to dimensionalise theories according to the range of specific instances that are explained by reference to it, we have argued that the range of specific applications to which TCE can be applied excludes transactions involving assets that are of an institutionally specific, socialised nature and does not apply in full to industries engaged in a rapid and constant cycle of innovation, such as those involved in the identification and development of popular music. Thus, hybrid governance modes such as joint ventures and partnerships are not a result of intermediate positions on asset specificity, monitoring difficulty, or environmental stability, rather they necessarily follow from the industry's conditions of institutional specificity, socialised construction, and rapid innovation cycles.

\section{Notes}

1. Defining long-term is a matter of subjective judgement. Williamson (1999) provides no guidance as to length, although we take his view that the potential for repeated exchanges between the two parties is the defining characteristic of such relationships.

2. Based on our own as yet unpublished interview data of personnel in majors and independents. 


\section{References}

Adler, M. (1984) "Stardom and Talent". The American Economic Review 75 (1): 208-212.

Amabile, T., Conti, R., Coon, H., Lazenby, J., and Herron, M. (1996) "Assessing the Work Environment for Creativity”. Academy of Management Journal 39 (5): 115-194.

Argyres, N. and Liebeskind, J. (1999) "Contractual Commitments, Bargaining Power, and Governance Inseparability: Incorporating History into Transaction Cost Theory". Academy of Management Review 24 (1): 49-63.

Baker, A. (1991) "A Model of Competition and Monopoly in the Record Industry". Journal of Cultural Economics 15: 29-54.

Barney, J. (1991) "Firm Resources and Sustained Competitive Advantage". Journal of Management 17 (1): 99-120.

Baumol, W. (1966) Performing Arts: The Economic Dilemma. MIT Press, Cambridge Mass.

Belinfante, A. and Johnson, R. (1982) "Competition, Pricing and Concentration in the U.S. Recorded Music Industry”. Journal of Cultural Economics 6(1): 11-24.

Breton, A. (1982) "Introduction to an Economics of Culture: A Liberal Approach", in Cultural Industries, UNESCO, Paris.

Buckley, P. and Carter, M. (1996) "The Economics of Business Process Design: Motivation, Information and Coordination within the Firm". International Journal of the Economics of Business 3(1): 5-35.

Burke, A. (1996) "The Dynamics of Product Differentiation in the British Record Industry". Journal of Cultural Economics 20 (2): 145-164.

Caves, R. (2000) Creative Industries: Contracts between Art and Commerce. Harvard Business Press, Cambridge, U.S.A.

Chiles, T. and McMackin, J. (1996) "Integrating Variable Risk Preferences, Trust and Transaction Cost Economics". Academy of Management Review 21 (1): 73-99.

Coase, R. (1992) “The Institutional Structure of Production". American Economic Review 82 (4): 713-719.

Cox, R., Felton, J., and Chung, K. (1995) "The Concentration of Commercial Success in Popular Music: An Analysis of the Distribution of Gold Records". Journal of Cultural Economics 19 (4): $330-340$.

Dequech, D. (2001) "Bounded Rationality, Institutions, and Uncertainty". Journal of Economic Issues 35 (4): 911-930.

Dewar, R. and Dutton, J. (1986) "The Adoption of Radical and Incremental Innovations: An Empirical Analysis". Management Science 32 (11): 1422-1433.

Dyer, J. (1997) "Effective Inter-Firm Collaboration: How Firms Minimise Transaction Costs and Maximise Transaction Value". Strategic Management Journal 18 (7): 535-557.

Elliot, M. (1993) Rockonomics: The Money behind the Music. Citadel Press, New York.

Faulkner, D. (1995) International Strategic Alliances: Co-operating to Compete. McGraw Hill, Maidenhead.

Foster, J. (2000) "Is There a Role for Transaction Cost Economics if We View Firms as Complex Adaptive Systems?" Contemporary Economic Policy 18 (4): 369-386.

Frith, S. (1990) Facing the Music; Essays on Pop, Rock and Culture. Mandarin, London.

Gander, J. and Rieple, A. (2002) "Creative Relationships in the Worldwide Recorded Music Industry". Creativity and Innovation Management 11 (4): 248-254.

Garnham, N. (1987) "Concepts of Culture - Public Policy and the Cultural Industries". Cultural Studies 1 (1): 54-61.

Ghoshal, S. and Moran, P. (1996) "Bad for Practice: A Critique of the Transaction Cost Theory". Academy of Management Review 21 (1): 13-47.

The Guardian (2000) "End of the Revolution". Alan McGee January 19th (p. 14). 
Gulati, R. (1995a) "Social Structure and Alliance Formation Patterns: A Longitudinal Analysis". Administrative Science Quarterly 40 (4): 619-643.

Gulati, R. (1995b) "Does Familiarity Breed Trust? The Implications of Repeated Transactions". Academy of Management Journal 38 (1): 85-113.

Gulati, R. (1998) "Alliances and Networks". Strategic Management Journal 19 (4): 293-317.

Granovetter, M. (1985) "Economic Action and Social Structure: A Theory of Embeddedness". American Journal of Sociology 91 (3): 481-510.

Grant, R. (1996) "Toward a Knowledge-Based Theory of the Firm”. Strategic Management Journal 17: $109-122$.

Hamlen, W. (1991) "Superstardom in Popular Music: Empirical Evidence". The Review of Economics and Statistics 73 (4): 729-733.

Hodgson, G. (1998) "Competence and Contract in the Theory of the Firm". Journal of Economic Behaviour and Organisation 35: 179-201.

Holmstrom B. and Roberts, J. (1998) "The Boundaries of the Firm Revisited". Journal of Economic Perspectives 12 (4): 73-95.

Hesmondhalgh, D. (1998) "The British Dance Music Industry: A Case Study of Independent Cultural Production". British Journal of Sociology 49 (2): 234-260.

Hirsch, P. (1972) "Processing Fads and Fashions: An Organisation-Set Analysis of Cultural Industry Systems". American Journal of Sociology 77 (4): 639-659.

International Federation of the Phonographic Industries (IFPI) (2001) The Recording Industry in Numbers 2001. IFPI, London.

Jones, G. (2001) "Towards a Positive Interpretation of Transaction Cost Theory: The Central Roles of Entrepreneurship and Trust”, in H. Freeman and H. Blackwell (eds.), The Handbook of Strategic Management. Oxford.

King, A. and Zeithaml, C. (2001) "Competences and Firm Performance: Examining the Causal Ambiguity Paradox". Strategic Management Journal 22: 75-99.

Kogut, B. and Zander, U. (1995) "Knowledge of the Firm and the Evolutionary Theory of the Multinational Corporation”. Journal of International Business Studies 24 (4): 625-646.

Kostova, T. (1999) "Transnational Transfer of Strategic Organisational Practices: A Contextual Perspective". The Academy of Management Review 24: 308-324.

Kretschmer, M., Klimis, G., and Choi, J. (1999) "Increasing Returns and Social Contagion in Cultural Industries". British Journal of Management 10: 61-72.

Lampel, J., Lant, T., and Shamsie, J. (2000) "Balancing Act: Learning from Organizing Practices in Cultural Industries”. Organisation Science 11 (3): 263-269.

Leifer, R. and Mills, P. (1996) "An Information Processing Approach for Deciding upon Control Strategies and Reducing Control Loss in Emerging Organisations". Journal of Management 22 (1): 113-137.

Lopes, P. (1992) "Innovation and Diversity in the Popular Music Industry, 1969 to 1990". American Sociological Review 57 (1): 56-71.

Lorange, P. and Roos, J. (1992) Strategic Alliances: Formation Evolution and Implementation. Blackwell, Oxford.

Lorenzoni, G. and Lipparini, A. (1999) "The Leveraging of Inter-Firm Relationships as a Distinctive Organisational Capability: A Longitudinal Study”. Strategic Management Journal 20 (4): 317338.

Madhok, A. (1997) "Cost, Value and Foreign Market Entry Mode: The Transaction and the Firm". Strategic Management Journal 18 (1): 39-61.

Moran, P. and Ghoshal, S. (1996) "Theories of Economic Organization: The Case for Realism and Balance". Academy of Management Review 21 (1): 58-73.

Mosakowski, E. (1998) "Entrepreneurial Resources, Organizational Choices, and Competitive Outcomes". Organization Science Nov/Dec, 9 (6): 625-643. 
Murray, J. and Kotabe, M. (1999) "Sourcing Strategies of U.S. Service Companies: A Modified Transaction Cost Analysis". Strategic Management Journal 20: 791-809.

Music Business International (December 1998) "Special Report on Independents".

Nassimbeni, G. (1998) "Network Structures and Co-ordination Mechanisms". International Journal of Operations and Production Management 18 (5/6): 538-555.

Negus, K. (1992) Producing Pop: Culture and Conflict in the Popular Music Industry. Edward Arnold, London.

Negus, K. (1999) Music Genres and Corporate Cultures. Routledge, London.

Nonaka, I. and Takeuchi, H. (1995) The Knowledge Creating Company. OUP, Oxford.

Noorderhaven, N. (1996) "How to Make TCE More Balanced and Realistic". Academy of Management Review 21 (4): 924-925.

Osborn, R. and Hagedoorn, J. (1997) "The Institutionalisation and Evolutionary Dynamics of InterOrganisational Alliances and Networks". Academy of Management Journal 40 (2): 261-278.

Passman, D. (1994) All You Need to Know about the Music Business. Simon and Schuster, New York.

Pessali, H. and Fernandez, R. (1999) "Institutional Economics at Micro Level? What Transaction Costs Theory Could Learn Form Original Institutionalism (in the Spirit of Building Bridges)'.' Journal of Economic Issues 33 (2): 265-275.

Peterson, R. and Berger, D. (1975) "Cycles of Symbol Production: The Case of Popular Music". American Sociological Review 40 (2): 158-173.

Phillips, N., Lawrence, T., and Hardy, C. (2000) "Inter-Organizational Collaboration and the Dynamics of Institutional Fields". Journal of Management Studies 37 (1): 23-44.

Pilditch, J. (1990) "Using Design Effectively", in P. Gorb (ed.), Design Management. Papers from the London Business School: Architecture Design and Technology Press, London.

Polanyi, M. (1966) The Tacit Dimension. Doubleday, New York.

Poole, M. and Van de Ven, A. (1989) "Using Paradox to Build Management and Organisation Theories". Academy of Management Review 14 (4): 562-578.

Porter, M. (1985) Competitive Advantage: Creating and Sustaining Superior Performance. Free Press, New York.

Powell, W. (1987) "Hybrid Organisational Arrangements: New Form or Transitional Development?" California Management Review 30 (1): 67-87.

Pratten, S. (1997) "The Nature of Transaction Cost Economics". Journal of Economic Issues XXXI (3): 781-803.

Rawsthorn, A. (1996) "Go! Discs Deal Marks Tensions in the Music World". Financial Times, London 23rd August.

Rieple, A. and Gander, J. (1999) "Strategic Relationships in the Worldwide Music Industry 19931999". Paper presented at the Journal of Economic Issues' business strategy and economics conference London, July 1999.

Rieple, A. Haberberg, A., and Gander, J. (2002) "Factors Contributing to the Effectiveness of Hybrid Organisational Forms; the Case of New Product Development". Refereed Paper track, British Academy of Management Conference, London.

Ricketts, M. (2001) “Trust and Economic Organisation”. Economic Affairs 21 (1): 18-23.

Rindfleisch, A. and Heide, J. (1997) "Transaction Cost Analysis: Past, Present, and Future Applications". Journal of Marketing 61 (4): 30-54.

Ring, P. and Van de Ven, A. (1992) "Structuring Co-operative Relationship between Organisations". Strategic Management Journal 13 (7): 483-498.

Rosen, S. (1981) “The Economics of Superstars”. American Economic Review 71 (5): 848-858.

Simon. H. (1957) "A Behavioural Model of Rational Choice", in Simon, Herbert A (ed.), Models of Man Wiley. New York.

Slater, G. and Spencer, D. (2000) "The Uncertain Foundations of Transaction Costs Economics". Journal of Economic Issues 34 (1): 61-87. 
Stinchcombe, A. (1959) "Bureaucratic and Craft Administration of Production: A Comparative Study". Administrative Science Quarterly 4: 168-187.

Strobl, E. and Tucker, C. (2000) "The Dynamics of Chart Success in the U.K. Pre-recorded Popular Music Industry". Journal of Cultural Economics 24 (2): 113-134.

Sutherland, J. (1975) Systems: Analysis, Administration and Architecture. Van Nostrand, New York.

Szulanski, G. (1995) "Unpacking Stickiness: An Empirical Investigation of the Barriers to Best Practice inside the Firm”. Academy of Management Journal Best Papers Proceedings, 437-442.

Taylor, S. (1998) “Arts: Whatever Happened to Britpop?” The Observer. London, 20th September.

Teece, D. (1998) "Capturing Value from Knowledge Assets: The New Economy, Markets for Knowhow and Intangible Assets". California Management Review 40 (3): 55-79.

Teece, D. (2000) "Strategies for Managing Knowledge Assets: The Role of Firm Structure and Industrial Context'.' Long Range Planning 33: 35-54.

Throsby, D. (1994) "The Production and Consumption of the Arts: A View of Cultural Economics". Journal of Economic Literature 32 (1): 1-29.

Towse, R. (1993) Singers in the Market Place: Economics of the Singing Profession. Clarendon Press, Oxford.

Towse, R. (1996) "Economics of Training Artists", in V. Ginsburgh and P. Menger (eds.), Economics of the Arts (Selected Essays). Elsevier Science, Amsterdam.

Weick, K. (1989) "Theory Construction as Disciplined Imagination". Academy of Management Review 14 (4): 516-531.

Wicks, A. Berman, S., and Jones, T. (1999) "The Structure of Optimal Trust: Moral and Strategic Implications". Academy of Management Review 24 (1): 99-116.

Williamson, O. (1973) "Markets and Hierarchies: Some Elementary Considerations". The American Economic Review (Papers and proceedings of the eighty-fifth meeting of the American Economic association) $63(2)$ : 316-325.

Williamson, O. (1975) Markets and Hierarchies. Free Press, New York.

Williamson, O. (1981) "The Economics of Organisation: The Transaction Cost Approach". American Journal of Sociology 87 (3): 548-577.

Williamson, O. (1985) The Economic Institutions of Capitalism. Free Press, New York.

Williamson, O. (1991) "Comparative Economic Organisation: The Analysis of Discrete Structural Alternatives". Administrative Science Quarterly 36 (2): 269-296.

Williamson, O. (1996) "Economic Organisation: The Case for Candor". Academy of Management Review 21 (1): 48-57.

Williamson, O. (1999) "Strategy Research: Governance and Competence Perspectives". Strategic Management Journal 20: 1087-1108.

Zajac, E. and Olsen, C. (1993) "From Transaction Cost to Transaction Value Analysis: Implications for the Study of Interorganisational Strategies". Journal of Management Studies 30 (1): 131-145. 